\title{
THE SIGNIFICANCE OF ELECTROCARDIOGRAMS OF LOW VOLTAGE $^{1}$
}

\author{
By HOWARD B. SPRAGUE AND PAUL D. WHITE \\ (From the Cardiac Clinic and Laboratory of the Massachusetts General Hospital)
}

(Received for publication June 18, 1926)

The introduction of electrocardiography into the clinical study of heart disease aroused the hope that a method might thereby be available for a quantitative measurement of myocardial power. But unfortunately because of the complicated electrical reaction which is expressed as a resultant in the waves of the electrocardiogram, it became evident that a close correlation was not to be expected between the power of the heart muscle and the amplitude of the electrical deflections of the galvanometer. Moreover it can be shown that fatally damaged hearts are capable of producing wide deviations of the string at a time when they are entirely powerless to provide an effective circulation to the body.

For some years, however, it has been shown by physiologists working with these problems, notably by Einthoven and his pupils, that in animal experiments, in which direct leads can be used and monophasic curves recorded, there is a correlation between the force of muscular contraction, including the heart beat, and the size of the electrical waves produced. In other words the electrical potential difference developed during muscular activity may be an index of the mechanical activity of the muscle.

This observation can not be transferred to the electrocardiogram in man, as recorded from the ordinary axial leads, for the reason that such records are diphasic and are not inscriptions of potential differences in the true electrical axis of the heart. They are in addition relatively crude and compound records of the contraction of a very complicated muscle structure the activity of whose various layers and syncytial connections defies analysis. 1926.

${ }^{1}$ Read by title at the meeting of the Society for Clinical Investigation, May, 
From a clinical standpoint, however, certain observed phenomena are deserving of note. It has been found that there are patients who show, electrocardiographically, the condition of "low voltage," which in our study we have taken to mean that the QRS. deflections of these patients do not deviate in either direction from the base line more than $5 \mathrm{~mm}$. in any of the three customary leads. In other words the difference in electrical potential is not greater than five ten thousandths of a volt.

Such a condition may be taken to mean one of two things, either that the electrical potential difference elaborated during contraction of the heart is actually small, or that the recorded difference is slight because of neutralizing effects within the cardiac muscle. (We are of course assuming a standardized string with a deviation of $1 \mathrm{~cm}$. for each millivolt of current.) Either explanation would seem to express an abnormality of contraction in that an actual low voltage means lessened contractile power and a diminished inscribed voltage suggests an asynergy of the units of the muscle mass. It must be realized, however, that such decrease of obvious potential difference may represent conduction defects of the intraventricular block type.

Whatever may be the explanation of this condition it is becoming more evident to those interested in clinical electrocardiography that the finding of records of low voltage is of important diagnostic and prognostic significance. Among those who have called attention to it are Carter (1), Pardee and Master (2), Lutembacher (3), White and Burwell (4), Oppenheimer and Rothschild (5), and Clerc and Bascourret (6). Thacher and White (7), Zondek (8) and others have noted its occurrence in myxedema and cretinism. Oppenheimer and Mann (9) reported seven cases in which it occurred in association with large pericardial or pleuro-pericardial effusions.

\section{MATERIAL}

With a view to determining the extent of its significance we have studied a series of 57 patients showing the condition. They comprise the total group in which it was observed at the Cardiographic Laboratory of the Massachusetts General Hospital from November 12, 1914, to November 1, 1925.

We have attempted to discover the conditions in which low volt- 
age is most commonly found, and to relate it to the clinical aspects of these patients and the progress of their diseases.

\section{Etiology}

One is struck immediately with the different incidence of the condition in the two sexes -40 are males and 17 females. This is explained when it is seen that this series falls readily into three main etiological groups: the arteriosclerotic (34 cases), the hypothyroid (10 cases), and the miscellaneous 13 cases.

Of the entire series of 57,22 are known to be dead (20 males and 2 females), 25 are living (13 males and 12 females), and 10 could not be traced ( 8 males and 2 females). Of those followed, therefore, about 47 per cent are dead.

The arteriosclerotic group is by far the most important. Of these, 29 are males and 5 are females. The well known preponderance of arteriosclerosis in males is the obvious explanation of the relative preponderance of males in the entire series. All but 6 of these patients suffered from congestive or anginal failure. Ten of them (all males) had had clinically definite coronary occlusion. Two others had rheumatic heart disease as well as arteriosclerosis. Ten cases. had a coexisting hypertension (i.e., a systolic blood pressure of over$160 \mathrm{~mm}$. of mercury was recorded) although probably more had had hypertension, but because of the heart failure the pressure had fallen. In 2 cases there was complete auriculo-ventricular dissociation, and in 3 cases a complicating neoplastic growth (carcinoma of rectum, prostate and stomach respectively).

In the hypothyroid group 6 had myxedema and 4 cretinism. Of the former 5 were female and 1 was male; of the latter 3 were female and 1 was male. One woman with myxedema had also rheumatic heart disease.

The miscellaneous group was composed of 13 cases in whom low voltage was found. The clinical diagnoses were as follows:

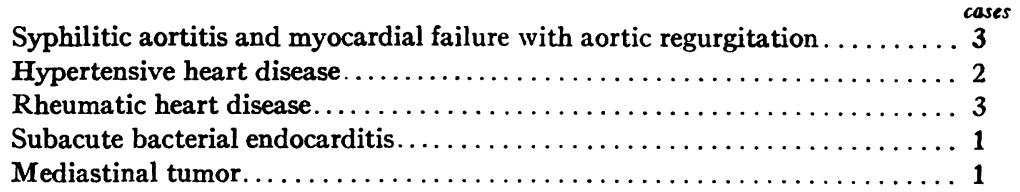


Mediastino-pericarditis................................... 1

Lymphatic leucemia (terminal stage) $\ldots \ldots \ldots \ldots \ldots \ldots \ldots \ldots \ldots \ldots \ldots \ldots$

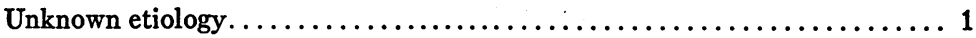

\section{The arteriosclerotic group}

This group comprises 34 cases. Eleven males and 1 female are known to be alive, 3 males and 4 females are untraced. Fifteen, or 44 per cent, are known to be dead and are all males. It is, however, very likely that 6 more, or a total of 61.7 per cent are also dead,

TABLE 1

\begin{tabular}{|c|c|c|c|}
\hline ... & Dead & Living & Untraced \\
\hline 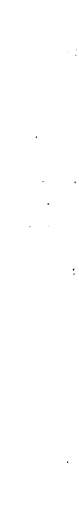 & $\begin{array}{l}49 \\
50 \\
53 \\
56 \\
59 \\
60 \\
60 \\
61 \\
62 \\
62 \\
64 \\
68 \\
73 \\
74 \\
84\end{array}$ & $\begin{array}{l}53 \\
54 \\
55 \\
50 \\
56 \\
60 \\
62 \\
62 \\
64 \\
64 \\
65 \\
68\end{array}$ & $\begin{array}{l}47 \\
54 \\
54^{*} \\
64 \\
65 \\
71^{*} \\
72^{*}\end{array}$ \\
\hline Total & .15 & 12 & 7 \\
\hline
\end{tabular}

* Almost certainly dead.

judging from their clinical conditions at the time of their last observations. In the entire sclerotic group 14 had mainly congestive failure, 10 had mainly anginal failure, 4 suffered from both congestive and anginal failure and 6 did not have either at the time of the record. (See table 1.)

A total of 9 out of the 11 males known to be alive have been reelectrocardiographed at least once during the course of the entire series. Two have not been reexamined; both have had coronary occlusion-one is working and one is not. The one woman known 
to be alive is doing well but has not been electrocardiographed again.

Of the 9 whose electrocardiograms have been repeated, 5 are working and 4 are not. Two have had coronary occlusion - the one in whom the low voltage persisted is not working; the other, who no longer shows low voltage, is working. Seven have not had evident coronary occlusion. Low voltage persists in 4 , of whom 2 are working and 2 are not. Low voltage has disappeared in 3;2 are working and 1 is not.

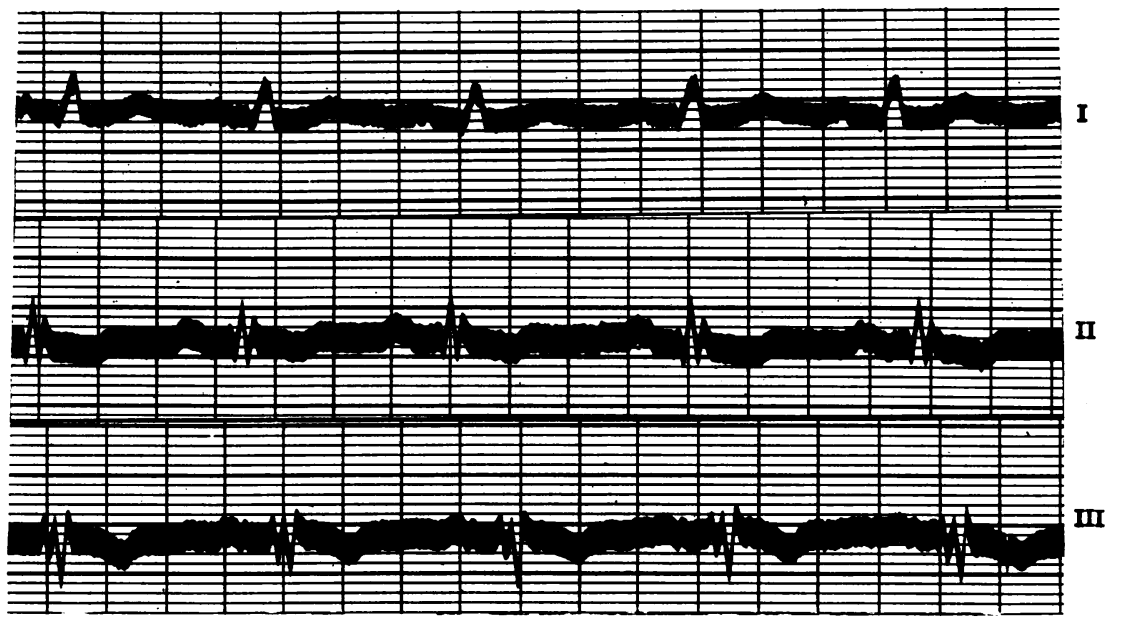

Fig. 1. C. F. W. Age 60. Male. Artertosclerotic and Hypertensive Heart Disease. Marked Congestive Failure and Pulsus Alternans. Low Voltage and INTraventricular Block

Summarizing the present condition of the 11 males known to be still living we find 6 able to work, and 5 not able to work. Two are working following evident coronary occlusion and 2 are not.

Fifteen patients are known to be dead. Of this group 11 died in less than 6 months after the discovery of low voltage, 13 died in less than a year, and all died in less than 2 years. The clinical prognosis was poor in all of these cases. 
The mode of death was as follows:

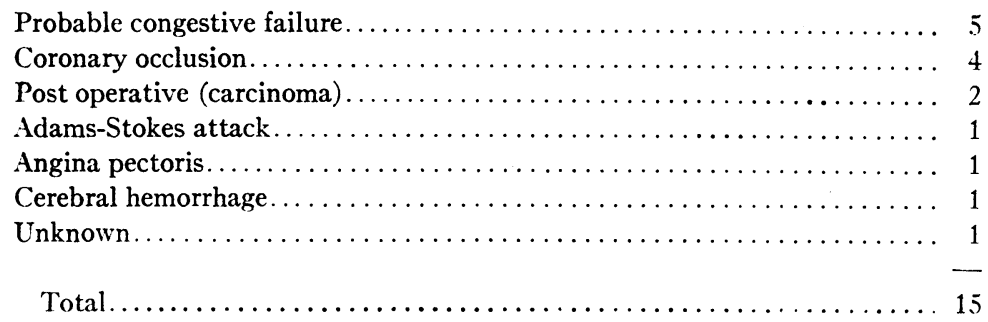

The quality of heart sounds was noted in 32 out of the total 34 cases of the sclerotic group. Table 2 shows the relation of heart sounds to mortality.

TABLE 2

\begin{tabular}{|c|c|c|c|c|}
\hline \multirow{2}{*}{ Heart sounds } & & \multicolumn{3}{|c|}{ Number of patients } \\
\hline & & Dead & Living & Untraced \\
\hline Good .............. & 3 & 3 & & \\
\hline Fair.... & 11 & 5 & 5 & 1 \\
\hline Poor $\ldots \ldots \ldots \ldots \ldots \ldots \ldots$ & 18 & 6 & 7 & 5 \\
\hline Not described $\ldots \ldots \ldots \ldots \ldots$ & 2 & 1 & & 1 \\
\hline Total. & 34 & 15 & 12 & 7 \\
\hline
\end{tabular}

It will be seen that 29 out of 32 in whom the auscultatory findings were noted had some diminution of the sounds. Eleven of those known to be dead had diminished heart sounds, but on the other hand the 3 in whom the heart sounds were of good quality are all dead. Those living all show an abnormal quality of their heart sounds.

Aberration of ventricular complexes, at times of a definite intraventricular or bundle-branch block type, was found in more than half of the cases in the sclerotic group. Its importance as a complication is shown in table 3 .

In the group of living patients an equal number showed aberration to be present or absent. Twice as many of those known to be dead showed aberration as did not; and of the patients with aberration, 
over one-half are known to have died, whereas one-third of those without it are dead.

Five patients had auricular fibrillation, 2 are dead, 2 alive and 1 untraced. Twenty-nine did not have fibrillation, 13 are alive, 10 are dead, and 6 untraced.

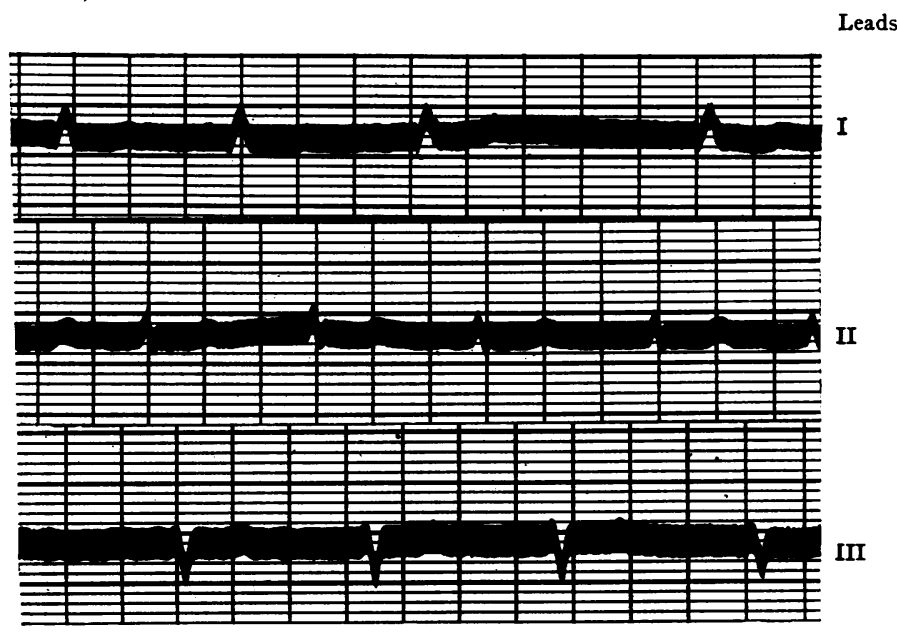

Fig. 2. W. M. Age 59. Male. Arteriosclerotic and Hypertensive Heart Disease. Auricular Fibrillation and Congestive Faiture. Very Small Complexes wrth Some Aberration

TABLE 3

\begin{tabular}{|c|c|c|}
\hline \multirow{2}{*}{ Condition of patient } & \multicolumn{2}{|c|}{ Aberration of complexes } \\
\hline & Present & Absent \\
\hline 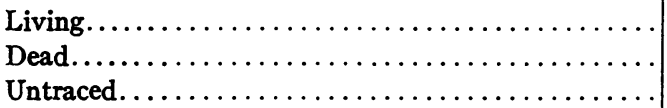 & $\begin{array}{r}6 \\
10 \\
3\end{array}$ & $\begin{array}{l}6 \\
5 \\
4\end{array}$ \\
\hline 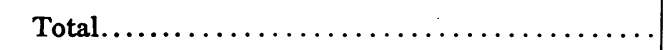 & 19 & 15 \\
\hline
\end{tabular}

It was thought that there might be some relation between low voltage and the activity of ventricular contraction as seen fluoroscopically. In 4 cases fluoroscopic notes are available. In one, a case of heart block, the independent pulsations of auricles and ventricles were 
described. Another heart was said to be beating regularly and the two chambers could be seen to contract normally. The third case

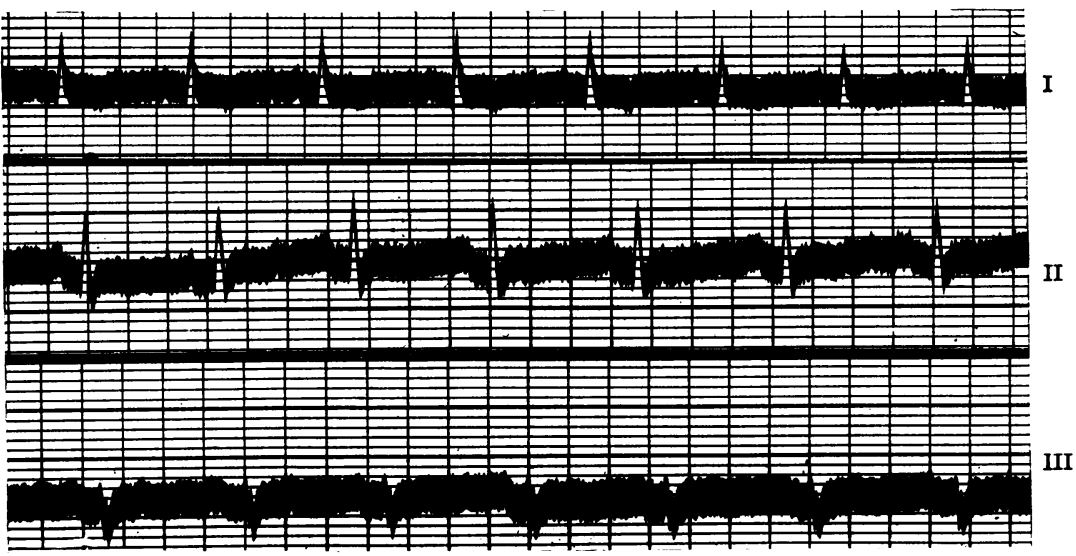

Fig. 3. E. R. Age 41. Female. Myxedema. Before Treatment

Leads

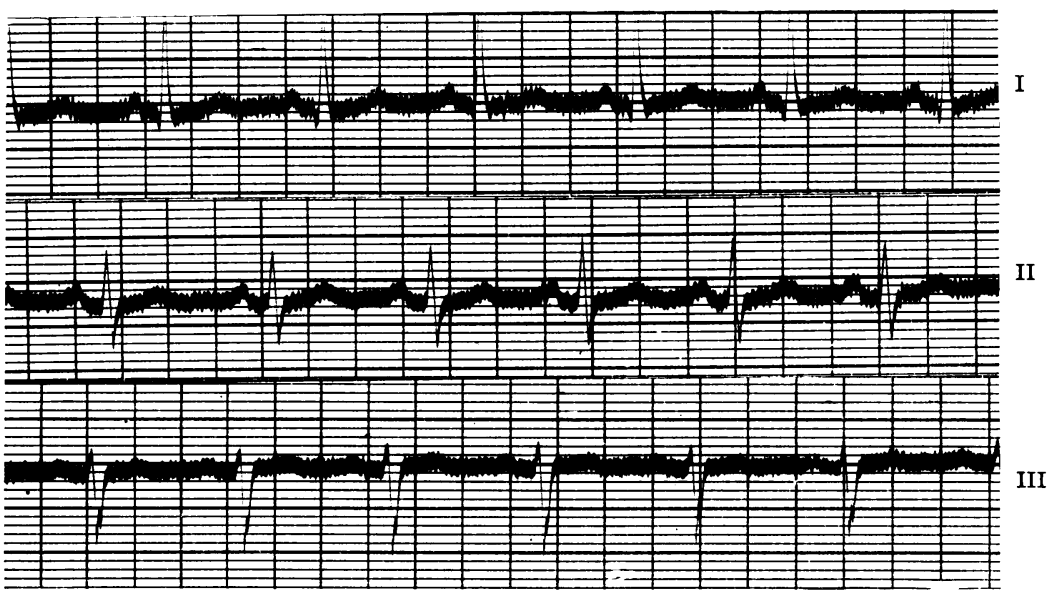

Fig. 4. E. R. Seven Years Later, Following Return to Normal with Thyrom Therapy. Left Axis Deviation

was said to show general enlargement of the heart with limited excursion of the left border; and the last case, the only one now alive, showed the pulsations of the various chambers visible but weak. 
Two cases were examined by autopsy. One showed arteriosclerotic thrombotic occlusion of branches of the coronary arteries; chronic

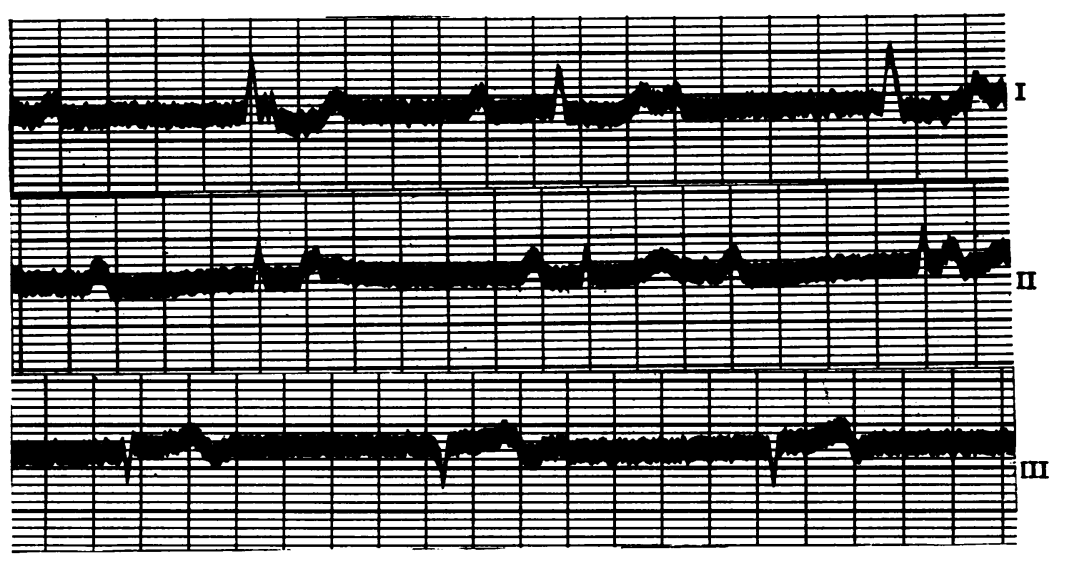

Fig. 5. K. M. Age 35. No Cinnical Evidence of Heart Disease. Smali Complexes and Complete Heart Block for the Past 9 Years. Some ABERRATION OF VeNTricular COMPLEXes

TABLE 4

\begin{tabular}{|c|c|c|c|c|}
\hline & Sex & Age & Diagnosis & $\begin{array}{l}\text { Last heard } \\
\text { from }\end{array}$ \\
\hline $1 *$ & M. & 54 & Arteriosclerosis with coronary disease & 1918 \\
\hline $2 *$ & F. & 64 & $\begin{array}{l}\text { Arteriosclerosis. Pulmonary embolus. } \\
\text { Auricular fibrillation }\end{array}$ & 1922 \\
\hline 3 & F. & 25 & Adult cretin & 1923 \\
\hline $4^{*}$ & M. & 42 & Luetic heart. Septicemia & 1924 \\
\hline $5^{*}$ & M. & 71 & Carcinoma of stomach. Arteriosclerosis & 1924 \\
\hline $6^{*}$ & F. & 65 & $\begin{array}{l}\text { Arteriosclerotic heart with congestive } \\
\text { failure }\end{array}$ & 1924 \\
\hline $7^{*}$ & F. & 54 & $\begin{array}{l}\text { Arteriosclerosis, angina pectoris and } \\
\text { congestive failure }\end{array}$ & 1924 \\
\hline $8^{*}$ & F. & 72 & $\begin{array}{l}\text { Arteriosclerotic heart disease with } \\
\text { marked congestive failure }\end{array}$ & 1924 \\
\hline 9 & M. & 32 & Chronic mediastino-pericarditis & 1925 \\
\hline .10 & M. & 47 & Coronary occlusion & 1925 \\
\hline
\end{tabular}

* Almost certainly dead.

interstitial myocarditis, myocardial infarction, mural thrombosis of the left ventricle, an area of epicardial softening in the right auricle, slight hemopericardium, thrombosis of a branch of the right pulmonary 
artery, infarcts of the lower lobe of the right lung, infarct of the right kidney, chronic pleuritis, and focal organizing pneumonia of the left lung.

The other case showed adenocarcinoma of the prostate with extension to neighboring bones, metastasis in retroperitoneal glands, diphtheritic cystitis, miliary abscesses of the kidneys, bronchopneumonia, arteriosclerosis of the coronary arteries, and thrombosis of the left iliac veins.

\section{The hypothyroid group}

Hypothyroidism has been known to cause changes in the electrocardiogram which are not necessarily of prognostic importance. Thacher and White (7) have recently analyzed a series of such patients showing the effects of treatment.

In our group there were 6 cases of myxedema. Four of these have been reelectrocardiographed and no longer show low voltage, following thyroid therapy. There were also four cretins. An increase in the amplitude of QRS. waves parallels clinical improvement in these cases.

In only 1 case of myxedema was a weakness of heart sounds noted, and in only 1 was there an especially abnormal x-ray description of the heart. In this case there was an increase in transverse diameter of the shadow with a suggestion of loss of tone of the muscle.

\section{The miscellaneous group}

Thirteen patients of variable etiology were placed in the miscellaneous group. Seven of them are know to have died and were obviously suffering from severe myocardial damage or weakness at the time the records were taken, 2 had syphilitic heart disease, and 1 each of rheumatic heart disease with uncontrollable flutter, hypertensive heart disease, subacute bacterial endocarditis, mediastinal tumor, and lymphatic leucemia. Two are untraced -1 with syphilitic heart disease and 1 with mediastino-pericarditis.

The 4 who are alive present some problems. One patient with mild hypertension and irritable heart has not had another record but is feeling well. Another with rheumatic heart disease is reported to be living a "bed and chair" life. The third one with rheumatic heart 
disease is no longer in the low voltage group and feels fairly well. The fourth one is a healthy woman of 35 who has had complete heart block and low voltage under observation for 9 years.

In this varied group 7 were said to have had very poor heart sounds, 1 case with definite gallop rhythm. Of these 4 are dead, 1 is living and 2 are untraced.

Three patents had auricular fibrillation and 1 an ectopic auricular rhythm. Aberrant ventricular complexes occurred in 2 .

\section{The untraced cases}

It is fair to assume that most of the cases which we have been unable to trace are dead, as appears from the résumé of diagnoses given in table 4. It is very likely that those patients marked with an asterisk are dead, or 7 out of 10 .

\section{DISCUSSION}

Blood pressure readings are not related in our series to the voltage of the electrocardiogram. Low voltage may be found with high, low, or normal systolic levels. Coronary occlusion, however, in some cases resulted in lowering of the blood pressure coincidental with the development of low voltage. In our series systolic pressures varied from 205 to 90 , and diastolic from 120 to 20 , or even lower in aortic regurgitation.

The QRS. complexes themselves were of various types. The first deflection was either negative or positive. In many the deflections alternated, making two or three small peaks, while in some the string, in a given lead, would move only in one direction from the base line.

The $T$ wave in lead 2 was never over $3 \mathrm{~mm}$. in height and in all but two it was $2 \mathrm{~mm}$. or less. On the original records of the patients it occurred as follows:

\begin{tabular}{l|c|c|c|c}
\hline & Upright $\mathrm{T}_{2}$ & Flat $\mathrm{T}_{2}$ & Inverted $\mathrm{T}_{2}$ & Diphasic $\mathrm{T}_{2}$ \\
\hline Number of cases..................... & 35 & 15 & 4 & 3 \\
\hline
\end{tabular}

Auricular fibrillation was present in 8 cases -3 are alive, 3 are dead, and 2 are untraced but probably dead. 


\section{SUMMARY AND CONCLUSIONS}

1. A study has been made of a series of 57 patients seen in the past 11 years at the Massachusetts General Hospital in whom electrocardiograms showed that the QRS. deflection was not greater than $5 \mathrm{~mm}$. from the base line in any lead. The electrocardiographic and clinical findings are correlated.

2. Low voltage has been found in 44 of these 57 cases ( 77 per cent) related to two conditions:

a. Myocardial failure from arteriosclerosis-34 cases.

b. Hypothyroidism-10 cases.

It has also occurred in our series in severely toxic or terminal myocardial states from rheumatic, syphilitic or hypertensive heart disease, mediastino-pericarditis, leucemia, and subacute bacterial endocarditis. In one case it was unexplained and was not incompatible with good health, but occurred in a young woman with complete heart block.

3. The arteriosclerotic group is most important. Only about onethird are known to be alive. 44 per cent are known to be dead and from the condition of those untraced at the time when they were last seen, it is fair to assume that almost two-thirds of the entire group are dead. In 10 cases it accompanied coronary occlusion. All patients known to be dead have died in less than two years after the finding of low voltage, although it is impossible to say how long it may have existed before it was recorded by the electrocardiograph. Those who are alive have all been living less than three years after the low voltage was found. The condition has disappeared in some cases with clinical improvement. The quality of the heart sounds was abnormal in 29 out of 32 patients in which they were described, and is one of the most typical findings in this condition.

4. Low voltage occurred in $\mathbf{1 0}$ cases of hypothyroidism. It disappeared in those reacting favorably to thyroid medication.

5. The decrease in amplitude of the QRS. complexes to $5 \mathrm{~mm}$. in patients in the miscellaneous group in terminal states of heart failure or with severely embarrassed cardiac action is further evidence that this finding is an important sign of myocardial weakness.

6. In the entire series, exclusive of the hypothyroid cases, only 9 
patients are able to carry on reasonable activity, but of these, two have had coronary occlusion and one has rheumatic heart disease with mitral stenosis.

7. Excluding the temporary effect in hypothyroidism low voltage has never been found, in our experience, in records from normal hearts. It is a finding of diagnostic and prognostic importance in forming an opinion of the myocardial ability of any individual.

\section{BIBLIOGRAPHY}

1. Carter, E. P.: Arch. Int. Med., 1918, xxii, 331. Further Observations on the Aberrant Electrocardiogram Associated with Sclerosis of the Atrioventricular Bundle Branches and Their Terminal Arborizations.

2. Pardee, H. E. B., and Master, A. M.: Jour. Amer. Med. Assoc., 1923, lxxx, 98. Electrocardiograms and Heart Muscle Disease. Also Master, A. M., and Pardee, H. E. B.: Arch. Int. Med., 1926, xxxvii, 42. The Effect of Heart Muscle Disease on the Electrocardiogram.

3. Lutembacher, R.: Bull. Med., 1922, xxxi, 616. The Heart in Hypertension.

4. White, P. D., and Burwell, C. S.: Med. Clin. North Amer., 1921, iv, 1839. The Clinical Significance of Changes in the Form of the Electrocardiogram.

5. Oppenheimer, B. S., and Rothschild, M. A.: Trans. Assoc. Amer. Physicians, 1924, xxxix, 247. The Value of the Electrocardiogram in the Diagnosis and Prognosis of Myocardial Disease.

6. Clerc, A., and Bascourret, M.: Rev. de Med., Paris, 1924, xli, 587. Les Anomalies des complexes ventriculaires electriques et leur importance pronostique dans le cours de l'insuffisance cardiaque.

7. Thacher, C., and White, P. D.: Amer. Jour. Med. Sci., 1926, clxxi, 61. The i" Electrocardiogram in Myxedema.

8. Zondek, H.: Munchen. med. Wchnschr., 1918, xlv, 1180. Herzbefunde bei endokrinen Erkrankungen.

9. Oppenheimer, B. S., and Mann, H.: Proc. Soc. for Exper. Biol. and Med., 1923, xx, 431. An Electrocardiographic Sign in Pericardial Effusion. 